\title{
Effects of Gut Microbiota and Ingredient-Ingredient Interaction on the Pharmacokinetic Properties of Rotundic Acid and Pedunculoside
}

\section{Authors}

Bao Yang ${ }^{1}$, Hui Li ${ }^{1}$, Qingfeng Ruan ${ }^{1}$, Shenxin Xuan ${ }^{1}$, Xiaojing Chen ${ }^{1}$, Hui Cui ${ }^{1}$, Zhongqiu Liu ${ }^{1}$, Jing Jin ${ }^{2}$, Zhongxiang Zhao ${ }^{1}$

Affiliations

1 School of Pharmaceutical Sciences, Guangzhou University of Chinese Medicine, Guangzhou, China

2 School of Pharmaceutical Sciences, Sun Yat-Sen University, Guangzhou, China

Key words

Ilex rotunda, Aquifoliaceae, llicis Rotundae Cortex, rotundic acid, pedunculoside, pharmacokinetic interactions, gut microbiota, antibacterial

received January 27, 2019

revised April 17, 2019

accepted April 24, 2019

\section{Bibliography}

DOI https://doi.org/10.1055/a-0902-5300

Published online June 5, 2019 | Planta Med 2019; 85: 729-

737 @ Georg Thieme Verlag KG Stuttgart · New York |

ISSN 0032-0943

\section{Correspondence}

Prof. Dr. Zhongxiang Zhao

School of Pharmaceutical Sciences, Guangzhou University of Chinese Medicine, Guangzhou Higher Education Mega Center 232 Waihuan East Road, Guangzhou 510006, China

Phone: + 862039358325 , Fax: + 862039358253

zzx37@163.com

Correspondence

Associate Professor Dr. Jing Jin

School of Pharmaceutical Sciences, Sun Yat-Sen University,

Guangzhou Higher Education Mega Center

132 Waihuan East Road, Guangzhou 510006, China

Phone: + 862039943034 , Fax: + 862039943000

jinjing@mail.sysu.edu.cn
丹 Supporting information available online at http://www.thieme-connect.de/products

\section{ABSTRACT}

Rotundic acid and pedunculoside are the most abundant constituents in Ilicis Rotundae Cortex, and possess lipid-lowering activity. In this study, we evaluated the pharmacokinetic interactions of rotundic acid with pedunculoside and other ingredients from Ilicis Rotundae Cortex with rotundic acid and pedunculoside, and preliminarily investigated the effects of gut microbiota on their pharmacokinetics using a pseudogerm-free rat model. After a single oral administration of each monomer, a monomer mixture, and llicis Rotundae Cortex extract to the conventional and pseudo-germ-free rats, rotundic acid and pedunculoside were quantified in plasma by an UPLC/Q-TOF-MS/MS method. The systemic exposure (maximum plasma concentration and area under concentrationtime curve) of two analytes in conventional rats were increased in an approximately dose-dependent manner. Oral administration of rotundic acid and pedunculoside in the forms of a monomer mixture and Ilicis Rotundae Cortex extract to the conventional rats significantly decreased the systemic exposure compared with the monomer groups, which demonstrated the existence of significant pharmacokinetic interactions. The pseudo-germ-free rats were prepared by nonabsorbable antibiotic treatment, and the systemic exposure of two analytes were significantly decreased and most of the "time to reach the maximum" values were delayed in comparison to conventional rats, therefore gut microbiota might serve as an efficient absorption promoter. These results provide a scientific basis for the clinical application of the two bioactive constituents and Ilicis Rotundae Cortex.

\section{Introduction}

Ilex rotunda Thunb., a medically woody plant in the Aquifoliaceae family, is widely distributed throughout southern China $[1,2]$. In the Chinese Pharmacopoeia (2015 edition) [3], its bark is officially recorded as IRC and is used for the treatment of gastrointestinal and cardiovascular diseases. IRC is a rich source of triterpenoids, which exhibit significant cardiovascular protection activities [1,
4-7]. Both PDC and its aglycone RA are by far the most abundant (approximately $23.5 \%$ of the IRC extract) and are representative medicinal triterpenoids in IRC that have been selected as the quality control markers $[8,9]$. Substantial lipid-lowering effects for PDC and RA have also been reported $[7,10]$. In this context, it is of great importance to investigate the pharmacokinetic properties of RA and PDC for a deep understanding of the pharmacological effects of the pure compounds as well as IRC. 


\begin{tabular}{|c|c|}
\hline \multicolumn{2}{|c|}{ ABBREVIATIONS } \\
\hline $\mathrm{AEH}$ & pseudo-germ-free rats administered with Ilicis \\
\hline AEL & $\begin{array}{l}\text { Rotundae Cortex extract at } 2000 \mathrm{mg} / \mathrm{kg} \\
\text { pseudo-germ-free rats administered with Ilicis } \\
\text { Rotundae Cortex extract at } 200 \mathrm{mg} / \mathrm{kg}\end{array}$ \\
\hline AMH & $\begin{array}{l}\text { pseudo-germ-free rats administered with } \\
\text { monomer mixture at } 470 \mathrm{mg} / \mathrm{kg}\end{array}$ \\
\hline AML & $\begin{array}{l}\text { pseudo-germ-free rats administered with } \\
\text { monomer mixture at } 47 \mathrm{mg} / \mathrm{kg}\end{array}$ \\
\hline APH & $\begin{array}{l}\text { pseudo-germ-free rats administered with } \\
\text { pedunculoside monomer at } 301 \mathrm{mg} / \mathrm{kg}\end{array}$ \\
\hline APL & $\begin{array}{l}\text { pseudo-germ-free rats administered with } \\
\text { pedunculoside monomer at } 30 \mathrm{mg} / \mathrm{kg}\end{array}$ \\
\hline ARH & $\begin{array}{l}\text { pseudo-germ-free rats administered with } \\
\text { rotundic acid monomer at } 226 \mathrm{mg} / \mathrm{kg}\end{array}$ \\
\hline ARL & $\begin{array}{l}\text { pseudo-germ-free rats administered with } \\
\text { rotundic acid monomer at } 23 \mathrm{mg} / \mathrm{kg}\end{array}$ \\
\hline ATM & antimicrobial \\
\hline AUC & area under concentration-time curve \\
\hline$C_{\max }$ & maximum plasma concentration \\
\hline IRC & Ilicis Rotundae Cortex \\
\hline IS & internal standard \\
\hline LLOQ & lower limit of quantification \\
\hline MRT & mean residence time \\
\hline NEH & conventional rats administered with Ilicis \\
\hline NEL & $\begin{array}{l}\text { Rotundae Cortex extract at } 2000 \mathrm{mg} / \mathrm{kg} \\
\text { conventional rats administered with Ilicis }\end{array}$ \\
\hline $\mathrm{NMH}$ & $\begin{array}{l}\text { Rotundae Cortex extract at } 200 \mathrm{mg} / \mathrm{kg} \\
\text { conventional rats administered with monomer } \\
\text { mixture at } 470 \mathrm{mg} / \mathrm{kg}\end{array}$ \\
\hline NML & $\begin{array}{l}\text { conventional rats administered with monomer } \\
\text { mixture at } 47 \mathrm{mg} / \mathrm{kg}\end{array}$ \\
\hline NPH & $\begin{array}{l}\text { conventional rats administered with } \\
\text { pedunculoside monomer at } 301 \mathrm{mg} / \mathrm{kg}\end{array}$ \\
\hline NPL & $\begin{array}{l}\text { conventional rats administered with } \\
\text { pedunculoside monomer at } 30 \mathrm{mg} / \mathrm{kg}\end{array}$ \\
\hline NRH & $\begin{array}{l}\text { conventional rats administered with rotundic } \\
\text { acid monomer at } 226 \mathrm{mg} / \mathrm{kg}\end{array}$ \\
\hline NRL & $\begin{array}{l}\text { conventional rats administered with rotundic } \\
\text { acid monomer at } 23 \mathrm{mg} / \mathrm{kg}\end{array}$ \\
\hline PDC & pedunculoside \\
\hline QC & quality control \\
\hline RA & rotundic acid \\
\hline SRM & selected reaction monitoring \\
\hline TCM & traditional Chinese medicine \\
\hline $\mathrm{T}_{\max }$ & time to reach the maximum \\
\hline$t_{1 / 2}$ & half-life \\
\hline
\end{tabular}

Due to the complexity of chemical constituents in TCMs, to some extent, herbal ingredient-ingredient and substance-ingredient pharmacokinetic interactions cannot be neglected, and that may significantly affect oral absorption and biological activity [11-13]. Therefore, it is important to illustrate those possible pharmacokinetic interactions after the administration of herbal ingredients or raw herbs. However, until now, the possible phar- macokinetic influences of other ingredients in IRC on RA and PDC, as well as the potential pharmacokinetic interaction between RA and PD, are seldom reported.

IRC and its ingredients are often given via the oral administration route, and are largely absorbed though the intestinal tract, so they will inevitably interact with the gut microbiota. A wealth of information shows that symbiotic gut microbiota represents an important bridge between host metabolism and environmental substances [14]. It is one of the most important places for the metabolism of TCMs before absorption into the blood due to the presence of numerous enzymes. Among the various reported enzymes, $\beta$-glucosidase is the most studied and highly produced intestinal bacterial enzyme [14-16]. Thus, compounds with a $\beta$-glucoside bond in IRC may be strongly affected after oral administration. Moreover, it is emphasized that gut microbiota can also indirectly influence the in vivo process of TCMs by affecting the intestinal absorption and the expression profiles of liver metabolic enzymes, which may influence their pharmacokinetics and pharmacodynamics [14-17].

Therefore, in this study, we established a pseudo-germ-free rat model to systemically investigate the potential effects of gut microbiota on the pharmacokinetic behaviors of RA and PDC. Moreover, after oral administration of each monomer, monomer mixture, and IRC extract to the conventional rats, we also compared the pharmacokinetic parameters of RA and PDC to evaluate the presence of possible pharmacokinetic interactions. It was expected that this experiment would contribute to improving clinical therapeutic effects and further pharmacological studies of RA, PDC, and IRC.

\section{Results and Discussion}

In our previous work [18], a UPLC/Q-TOF-MS/MS method was established for quantification analysis of six triterpenoids in rat plasma after oral administration of IRC extract. Here, using the developed LC-MS method as the starting point, the chromatographic conditions were further modified to shorten the run time. The mass spectrometer was performed in the SRM model, and the ion transition and collision energy values for RA, PDC, and IS were $\mathrm{m} / \mathrm{z} \quad 487.34 \rightarrow 469.33$ and $-47 \mathrm{eV}, \mathrm{m} / \mathrm{z} \quad 695.40 \rightarrow 487.34$ and $-38 \mathrm{eV}$, and $\mathrm{m} / \mathrm{z} 825.40 \rightarrow 649.36$ and $-55 \mathrm{eV}$, respectively. The representative MS/MS spectra of two analytes under the optimized conditions are shown in $>$ Fig. 1 B, C.

As shown in $>$ Fig. 2, the retention times of RA, PDC, and IS were about $2.83,1.68$, and $1.44 \mathrm{~min}$, respectively, and no interfering peaks were observed. The calibration curves were $y=0.00731 x+$ 0.01632 for RA and $y=0.01185 x+0.05717$ for PDC. Linearity was confirmed over the whole calibration range $(2.88-2400 \mathrm{ng} / \mathrm{mL}$ for RA and $1.52-800 \mathrm{ng} / \mathrm{mL}$ for PDC) with correlation coefficient values of 0.9920 for RA and 0.9978 for PDC. The LLOQs for RA and PDC were 2.88 and $1.52 \mathrm{ng} / \mathrm{mL}$, respectively. The precisions of two analytes (Table 1S, Supporting Information) were less than 12.2 and $13.3 \%$, whilst the accuracy ranged from -12.6 to $12.3 \%$. The extraction recovery of two analytes varied from 86.3 to $110.3 \%$, while the matrix effect ranged from 86.6 to $109.7 \%$ (Table $2 \mathrm{~S}$, Supporting Information). The results of the stability tests are summarized in Table 3S, Supporting Information, within the ac- 
A

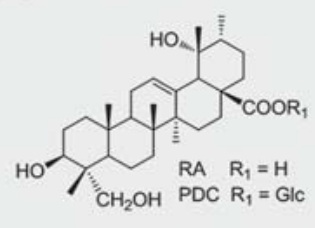

B

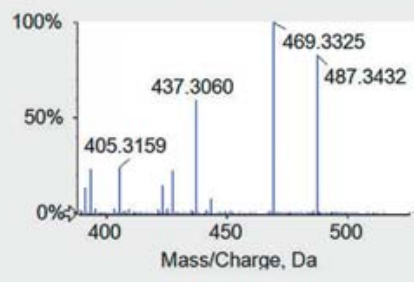

C

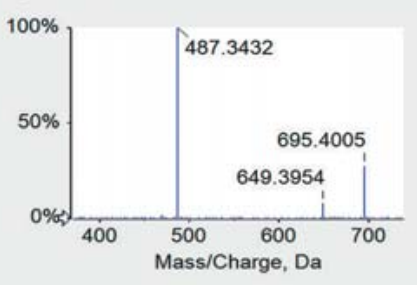

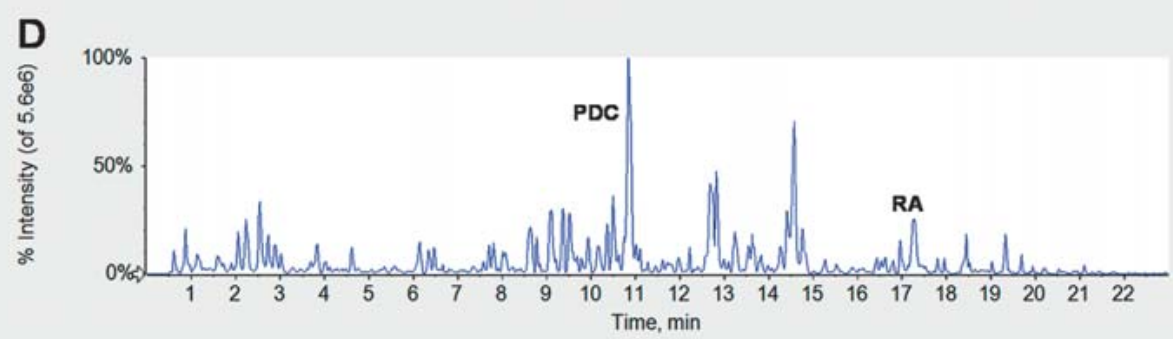

- Fig. 1 A Chemical structures of RA and PDC; representative MS/MS spectra of RA (B) and PDC (C). D Representative total ion chromatogram of IRC extract in the negative ESI mode. IRC, llicis Rotundae Cortex; PDC, pedunculoside; RA, rotundic acid.

A
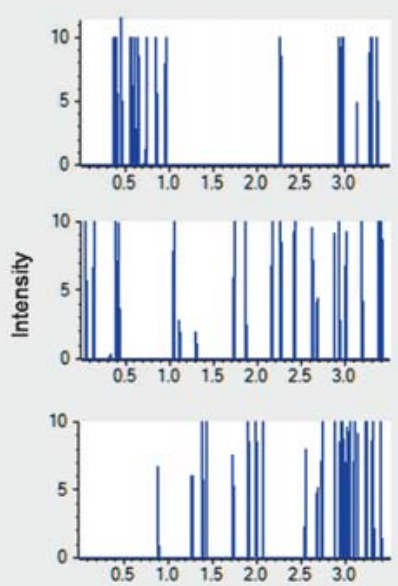

B
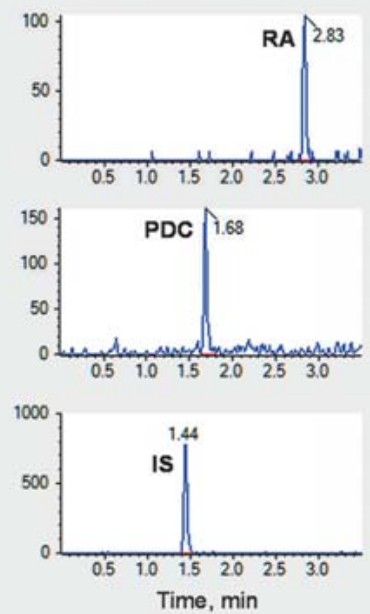

C
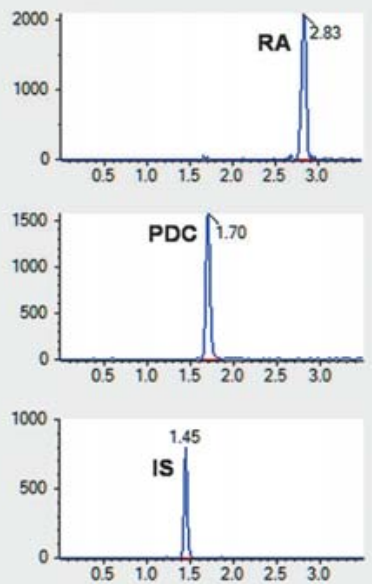

- Fig. 2 Representative extract ion chromatograms of RA, PDC, and IS in rat plasma. A Blank plasma; B blank plasma spiked with two analytes in LLOQ and IS; C plasma sample from a rat after a single oral administration of IRC extract. IRC, llicis Rotundae Cortex; IS, internal standard; LLOQ, lower limit of quantification; PDC, pedunculoside; RA, rotundic acid.

ceptable criteria of $\pm 15 \%$. All results demonstrated that the optimized analytical method was sensitive and reproducible.

Compared with the conventional rats, most of the ATM-treated rats developed diarrhea after oral administration with the antibiotic mixture for 7 consecutive days. The metabolic activity of gut microbiota was directly evaluated by analysis of the $\beta$-glucosidase activity in feces samples. Experimental data showed that the $\beta$-glucosidase activity in the conventional group $(0.93 \pm$ $0.21 \mathrm{nmol} / \mathrm{min} / \mathrm{mg})$ was significantly higher $(p<0.01)$ than in the ATM-treated group $(0.27 \pm 0.06 \mathrm{nmol} / \mathrm{min} / \mathrm{mg})$, which confirmed the validity of the pseudo-germ-free rat model.
This developed UPLC/Q-TOF-MS/MS method was successfully employed to quantify the plasma concentrations of RA and PDC. The mean plasma concentration-time profiles of RA and PDC are presented in $\mathbf{F i g s .} 3$ and $\mathbf{4}$, and part of them showed two or three peaks. The most reasonable explanation might be the enteric circulation, inhomogeneity of intestinal absorption, gastric motility and so on, and this phenomenon was common in the pharmacokinetic studies of TCMs $[11,19]$. The major pharmacokinetic parameters of $C_{\max }, T_{\max }, t_{1 / 2}$, AUC, and MRT are summarized in $>$ Tables 1 and 2. 

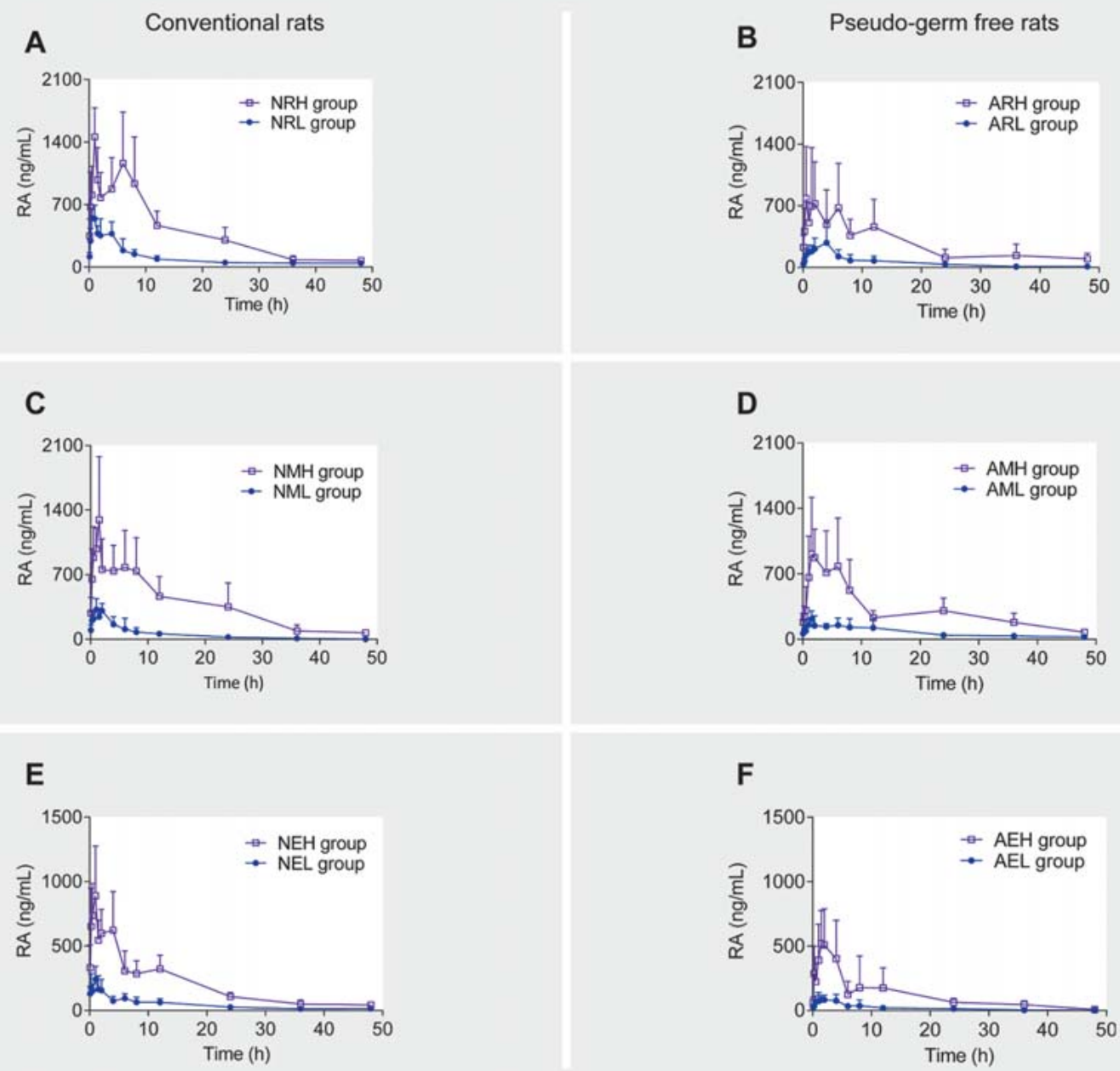

- Fig. 3 Mean plasma concentration-time curves of RA in conventional and pseudo-germ-free rat plasma after a single oral administration of RA ( $A$ and $B$ ), the monomer mixture ( $C$ and $D$ ), and IRC extract (E and F) at two dose levels. IRC, llicis Rotundae Cortex; RA, rotundic acid.

We first investigated the pharmacokinetic behaviors of RA and PDC in conventional rats after oral administration of each monomer, monomer mixture, and IRC extract at two dose levels. Overall, the systemic exposure $\left(C_{\max }\right.$ and $\left.A U C\right)$ of RA and PDC in conventional rats seemed to increase in a dose-dependent manner over the two dose levels, although not necessarily dose proportional, while no clear trend was observed for $T_{\max }, t_{1 / 2 z}$, and MRT (0-t). After oral administration of the RA monomer to the conventional rats, the mean $C_{\max }$ values were reached within $1.3 \mathrm{~h}$ and amounted to $1689.5 \pm 402.6$ and $627.2 \pm 110.4 \mathrm{ng} / \mathrm{mL}$ at the doses of $462 \mu \mathrm{mol} / \mathrm{kg}$ and $46 \mu \mathrm{mol} / \mathrm{kg}$, respectively, and the corresponding mean $\mathrm{AUC}_{0-\mathrm{t}}$ values were $21024.2 \pm 5661.6$ and $4908.4 \pm 1150.3 \mathrm{ng} \mathrm{h} / \mathrm{mL}$, respectively. When the PDC monomer was orally administered to the conventional rats at doses equivalent to the RA monomer, the mean $C_{\max }$ values were reached within $1.8 \mathrm{~h}$ and amounted to $513.5 \pm 100.6$ and $115.8 \pm 34.6 \mathrm{ng} /$ $\mathrm{mL}$, respectively, and the corresponding mean $\mathrm{AUC}_{0-\mathrm{t}}$ values were $4811.9 \pm 785.9$ and $673.6 \pm 319.4 \mathrm{ng}$ h/mL, respectively. A longer mean $T_{\max }$ and lower systemic exposure for PDC were observed compared with RA. This phenomenon may be explained by their different chemical structures, which the attachment of one sugar moiety remarkably reduced the rate of absorption and decreased the systemic exposure, and the molecular mass of PDC was about $650 \mathrm{Da}$, which was slightly greater than the favorable value [20, 21].

In the comparative pharmacokinetics studies, the systemic exposure of RA and PDC in conventional rats was remarkably decreased when orally administrated the monomer mixture or IRC extract ( $\vee$ Tables $\mathbf{1}$ and 2 ). Specifically, in comparison with the relevant monomer groups, when administered with monomer mixture at 470 and $47 \mathrm{mg} / \mathrm{kg}$, the mean $C_{\max }$ values of RA were decreased by 14 and $41 \%$, respectively, and the corresponding mean $\mathrm{AUC}_{0-\mathrm{t}}$ values were decreased by 18 and $49 \%$, respectively. The dose-normalized mean $C_{\text {max }}$ values of PDC were decreased by 45 and $19 \%$, respectively, and the corresponding dose-normalized mean $\mathrm{AUC}_{0-\mathrm{t}}$ values were decreased by 46 and $14 \%$, respectively. As compared with the relevant monomer groups, when administered with the IRC extract at 2000 and $200 \mathrm{mg} / \mathrm{kg}$, the mean $C_{\max }$ values of RA were decreased by 38 and $54 \%$, respectively, and the corresponding $\mathrm{AUC}_{0-\mathrm{t}}$ values were decreased by 55 and $58 \%$, re- 

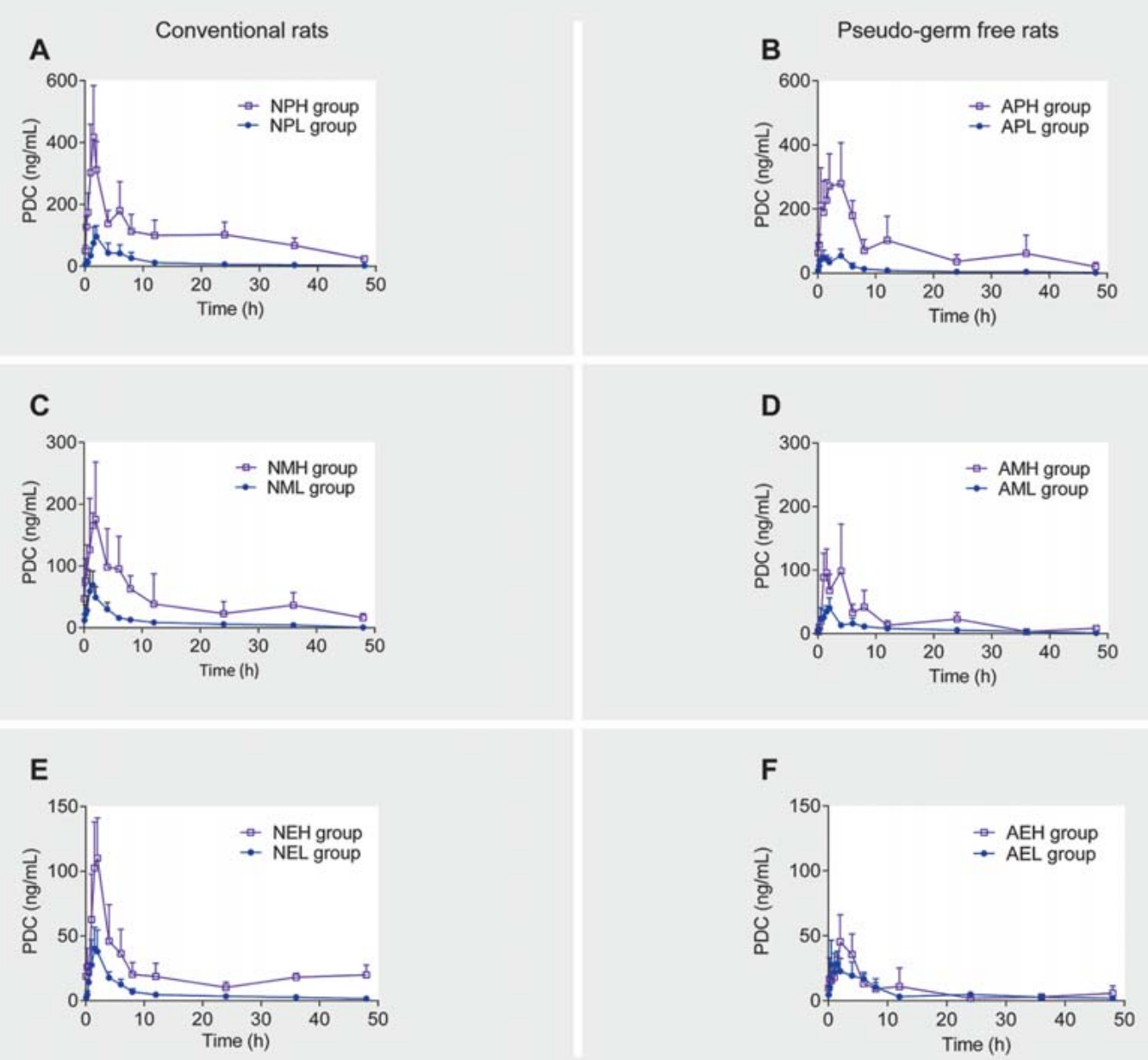

- Fig. 4 Mean plasma concentration-time curves of PDC in conventional and pseudo-germ-free rat plasma after a single oral administration the PDC monomer ( $\mathrm{A}$ and $\mathrm{B})$, monomer mixture ( $\mathrm{C}$ and $\mathrm{D})$, and IRC extract (E and $\mathrm{F}$ ) at two dose levels. IRC, llicis Rotundae Cortex; PDC, pedunculoside.

spectively. The dose-normalized mean $C_{\max }$ values of PDC were decreased by 69 and $47 \%$, respectively, and the corresponding dose-normalized mean $\mathrm{AUC}_{0-\mathrm{t}}$ values were decreased by about 73 and $48 \%$, respectively. Consequently, the above results not only indicated a remarkable pharmacokinetic interaction between the RA and PDC monomers, but also provided evidence suggesting that some other ingredients from the IRC might have a negative impact on the systemic exposure of RA and PDC, and might subsequently degrade their bioavailability. The reason might be that RA, PDC, and other ingredients in the IRC had very similar chemical structures, resulting in the competitive absorption that appeared in the small intestine.

An increasing number of studies suggest that gut microbiota plays an important role in the absorption and metabolism of TCMs after oral administration [14-16]. Thus, we established a pseudogerm-free rat model to evaluate whether the pharmacokinetics of RA and PDC were affected by the gut microbiota. As shown in - Tables 1 and 2, it was obvious that the mean $C_{\max }$ and AUC values of RA and PDC in pseudo-germ-free rats were decreased and most of the mean $T_{\max }$ values were delayed (about $0.5 \mathrm{~h}$, except for PDC in the APL and AMH groups) by comparison with the con- ventional rats, while the other pharmacokinetic parameters did not show significant differences. The mean $C_{\max }$ values of $R A$ in the ARH, ARL, AMH, AML, AEH, and AEL groups were decreased by $26,38,12,35,21$, and $56 \%$ compared with the conventional groups, respectively, and the corresponding mean $\mathrm{AUC}_{0-\mathrm{t}}$ values were decreased by $40,44,15,8,41$, and $57 \%$, respectively. Similarly, in comparison with the conventional groups, the mean $C_{\max }$ values of PDC in the $\mathrm{APH}, \mathrm{APL}, \mathrm{AMH}, \mathrm{AML}, \mathrm{AEH}$, and $\mathrm{AEL}$ groups were decreased by $32,48,41,35,64$, and $18 \%$, respectively, and the corresponding mean $\mathrm{AUC}_{0-\mathrm{t}}$ values were decreased by 19,31 , $51,25,63$, and $19 \%$, respectively. Therefore, with regard to the potential ingredient-ingredient pharmacokinetic interactions, it was confirmed that the gut microbiota could significantly affect the pharmacokinetic behaviors of RA and PDC, which might be directly correlated with marked changes in biological activity. The exact mechanisms were unclear, but it was speculated that the gut microbiota might serve as an efficient absorption promoter contributing to the high systemic exposure of RA and PDC. In addition, considering that the gut microbiota was susceptible to the antibiotics, if not absolutely necessary, the combined application of antibiotics with IRC, RA, and PDC should be avoided. 
- Table 1 Pharmacokinetic parameters of RA after a single oral administration of the RA monomer, monomer mixture, and IRC extract to conventional and pseudo-germ-free rats at two dose levels (mean $\pm S D, n=6$ ).

\begin{tabular}{|c|c|c|c|c|c|c|c|}
\hline \multirow{2}{*}{$\begin{array}{l}\text { Parame- } \\
\text { ters }\end{array}$} & \multirow[t]{2}{*}{ Unit } & \multicolumn{2}{|l|}{ RA monomer } & \multicolumn{2}{|c|}{ Monomer mixture of RA and PDC } & \multicolumn{2}{|l|}{ IRC extract ${ }^{\mathrm{a}}$} \\
\hline & & $\begin{array}{l}226 \mathrm{mg} / \mathrm{kg} \\
(462 \mu \mathrm{mol} / \mathrm{kg})\end{array}$ & $\begin{array}{l}23 \mathrm{mg} / \mathrm{kg} \\
(46 \mu \mathrm{mol} / \mathrm{kg})\end{array}$ & 470 mg/kg & $47 \mathrm{mg} / \mathrm{kg}$ & $2000 \mathrm{mg} / \mathrm{kg}$ & 200 mg/kg \\
\hline \multicolumn{2}{|c|}{ Conventional rats } & NRH group & NRL group & NMH group & NML group & NEH group & NEL group \\
\hline$C_{\max }$ & $\mathrm{ng} / \mathrm{mL}$ & $1689.5 \pm 402.6$ & $627.2 \pm 110.4$ & $1458.8 \pm 538.6$ & $368.6 \pm 75.6^{\# \#}$ & $1041.5 \pm 293.6^{\#}$ & $289.1 \pm 77.4^{\# \# \Delta}$ \\
\hline $\mathrm{T}_{\max }$ & $\mathrm{h}$ & $1.3 \pm 0.4$ & $1.1 \pm 0.3$ & $1.4 \pm 0.4$ & $1.2 \pm 0.3$ & $1.0 \pm 0.6$ & $1.1 \pm 0.4$ \\
\hline$t_{1 / 2 z}$ & h & $12.3 \pm 2.1$ & $10.6 \pm 2.2$ & $9.0 \pm 3.3$ & $8.5 \pm 2.0$ & $10.4 \pm 4.6$ & $16.3 \pm 2.3$ \\
\hline$A \cup C_{(0-t)}$ & $\mathrm{ng} \mathrm{h/mL}$ & $21024.2 \pm 5661.6$ & $4908.4 \pm 1150.3$ & $17280.1 \pm 6063.4$ & $2492.5 \pm 606.9^{\# \#}$ & $9360.9 \pm 1485.3^{\# \# \Delta}$ & $2083.7 \pm 587.6^{\# \#}$ \\
\hline $\mathrm{AUC}_{(0-\infty)}$ & $\mathrm{ng} h / \mathrm{mL}$ & $23274.5 \pm 5363.3$ & $6181.5 \pm 1323.2$ & $17931.7 \pm 6012.4$ & $2530.2 \pm 594.5^{\# \#}$ & $9852.0 \pm 1299.1^{\# \# \Delta}$ & $2383.9 \pm 579.7^{\# \#}$ \\
\hline $\operatorname{MRT}_{(0-t)}$ & h & $12.9 \pm 1.4$ & $13.6 \pm 1.9$ & $13.8 \pm 1.9$ & $9.5 \pm 2.3$ & $12.2 \pm 2.3$ & $12.5 \pm 2.7$ \\
\hline \multicolumn{2}{|c|}{ Pseudo-germ-free rats } & ARH group & ARL group & AMH group & AML group & AEH group & AEL group \\
\hline$C_{\max }$ & $\mathrm{ng} / \mathrm{mL}$ & $1242.4 \pm 528.9$ & $389.4 \pm 178.4^{*}$ & $1287.9 \pm 343.4$ & $238.6 \pm 72.3^{*}$ & $823.2 \pm 106.7^{\# \# \Delta}$ & $128.1 \pm 29.5^{* * \# \# \Delta}$ \\
\hline $\mathrm{T}_{\max }$ & h & $2.1 \pm 1.5$ & $2.5 \pm 1.4$ & $2.0 \pm 1.2$ & $2.1 \pm 1.0$ & $2.1 \pm 1.1$ & $1.9 \pm 1.2$ \\
\hline$t_{1 / 2 z}$ & h & $15.2 \pm 8.2$ & $12.8 \pm 7.7$ & $15.2 \pm 5.2$ & $16.1 \pm 6.5$ & $7.3 \pm 2.0$ & $16.8 \pm 7.3$ \\
\hline$A \cup C_{(0-t)}$ & $\mathrm{ng} \mathrm{h} / \mathrm{mL}$ & $12531.9 \pm 5627.1^{*}$ & $2757.9 \pm 1485.3^{*}$ & $14747.9 \pm 4064.7$ & $2283.6 \pm 856.7$ & $5560.9 \pm 1752.1^{* * \# \Delta \Delta}$ & $904.3 \pm 528.8^{* * \# \Delta \Delta}$ \\
\hline $\mathrm{AUC}_{(0-\infty)}$ & $\mathrm{ng} \mathrm{h} / \mathrm{mL}$ & $14829.5 \pm 8035.6^{*}$ & $2931.6 \pm 1477.5^{*}$ & $16424.1 \pm 3094.4$ & $2198.6 \pm 782.1$ & $5595.9 \pm 1350.4^{* * \# \Delta \Delta}$ & $980.7 \pm 478.8^{* * \# \Delta \Delta}$ \\
\hline $\operatorname{MRT}_{(0-\mathrm{t})}$ & $\mathrm{h}$ & $14.86 \pm 2.6$ & $11.3 \pm 1.5$ & $16.5 \pm 2.2$ & $15.4 \pm 3.7$ & $12.2 \pm 2.2$ & $9.9 \pm 1.8$ \\
\hline
\end{tabular}

a Oral administration of the monomer mixture at 470 and $47 \mathrm{mg} / \mathrm{kg}$, and IRC extract at 2000 and $200 \mathrm{mg} / \mathrm{kg}$ were equivalent to that of the oral administration of the RA monomer at 226 and $23 \mathrm{mg} / \mathrm{kg}$, respectively. ${ }^{*} \mathrm{P}<0.05$ and ${ }^{*} \mathrm{*} p<0.01$ when compared with the level of the corresponding group of conventional rats; ${ }^{\#} p<0.05$ and ${ }^{\# \#} p<0.01$ when compared with the corresponding group that was orally administrated the RA monomer; ${ }^{\Delta} p<0.05$ and ${ }^{\triangle} p<0.01$ when compared with the corresponding group that was orally administrated the monomer mixture

- Table 2 Pharmacokinetic parameters of PDC after a single oral administration of the PDC monomer, monomer mixture, and IRC extract to conventional and pseudo-germ-free rats at two dose levels (mean $\pm S D, n=6)$.

\begin{tabular}{|c|c|c|c|c|c|c|c|}
\hline \multirow{2}{*}{$\begin{array}{l}\text { Parame- } \\
\text { ters }\end{array}$} & \multirow[t]{2}{*}{ Unit } & \multicolumn{2}{|l|}{ PDC monomer } & \multicolumn{2}{|c|}{ Monomer mixture of RA and PDCa } & \multicolumn{2}{|l|}{ IRC extract ${ }^{a}$} \\
\hline & & $\begin{array}{l}301 \mathrm{mg} / \mathrm{kg} \\
(462 \mu \mathrm{mol} / \mathrm{kg})\end{array}$ & $\begin{array}{l}30 \mathrm{mg} / \mathrm{kg} \\
(46 \mu \mathrm{mol} / \mathrm{kg})\end{array}$ & $470 \mathrm{mg} / \mathrm{kg}$ & 47 mg/kg & $2000 \mathrm{mg} / \mathrm{kg}$ & $200 \mathrm{mg} / \mathrm{kg}$ \\
\hline \multicolumn{2}{|c|}{ Conventional rats } & NPH group & NPL group & NMH group & NML group & NEH group & NEL group \\
\hline$C_{\max }$ & $\mathrm{ng} / \mathrm{mL}$ & $513.5 \pm 100.6$ & $115.8 \pm 34.6$ & $228.3 \pm 58.8^{\# \#}$ & $75.7 \pm 22.7$ & $128.7 \pm 28.8^{\# \# \Delta \Delta}$ & $50.2 \pm 12.8^{\# \#}$ \\
\hline $\mathrm{T}_{\max }$ & h & $1.5 \pm 0.4$ & $1.8 \pm 0.3$ & $1.6 \pm 0.4$ & $1.5 \pm 0.6$ & $1.6 \pm 0.4$ & $1.6 \pm 0.4$ \\
\hline$t_{1 / 2 z}$ & h & $14.2 \pm 1.8$ & $15.3 \pm 7.0$ & $15.8 \pm 6.2$ & $10.7 \pm 4.0$ & $21.4 \pm 4.5$ & $20.2 \pm 4.1$ \\
\hline$A \cup C_{(0-t)}$ & $\mathrm{ngh} / \mathrm{mL}$ & $4811.9 \pm 785.9$ & $673.6 \pm 319.4$ & $2121.5 \pm 608.7^{\# \#}$ & $468.7 \pm 119.6$ & $1071.4 \pm 142.7^{\# \# \Delta \Delta}$ & $283.9 \pm 66.9^{\# \Delta}$ \\
\hline $\mathrm{AUC}_{(0-\infty)}$ & $\mathrm{ngh} / \mathrm{mL}$ & $6228.7 \pm 1293.6$ & $753.6 \pm 287.1$ & $2980.9 \pm 458.5^{\# \#}$ & $483.2 \pm 113.9^{\#}$ & $2327.5 \pm 879.3^{\# \#}$ & $340.6 \pm 64.1$ \\
\hline $\mathrm{MRT}_{(0-t)}$ & h & $17.1 \pm 1.7$ & $11.2 \pm 2.2$ & $16.3 \pm 3.5$ & $11.5 \pm 2.2$ & $18.8 \pm 2.1$ & $11.8 \pm 1.6$ \\
\hline \multicolumn{2}{|c|}{ Pseudo-germ-free rats } & APH group & APL group & AMH group & AML group & AEH group & AEL group \\
\hline$C_{\max }$ & $\mathrm{ng} / \mathrm{mL}$ & $349.9 \pm 75.7^{*}$ & $60.1 \pm 19.2^{*}$ & $133.9 \pm 62.9 * \# \#$ & $48.9 \pm 8.1^{*}$ & 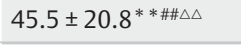 & $40.9 \pm 7.7^{\#}$ \\
\hline $\mathrm{T}_{\max }$ & h & $2.1 \pm 1.2$ & $1.7 \pm 1.4$ & $1.8 \pm 1.1$ & $2.3 \pm 0.7$ & $2.3 \pm 0.6$ & $2.2 \pm 0.8$ \\
\hline$t_{1 / 2 z}$ & h & $18.6 \pm 6.8$ & $12.4 \pm 6.3$ & $11.6 \pm 3.9$ & $14.4 \pm 7.5$ & $15.6 \pm 4.4$ & $23.1 \pm 7.0$ \\
\hline$A \cup C_{(0-t)}$ & $\mathrm{ng} \mathrm{h} / \mathrm{mL}$ & $3904.2 \pm 1627.1$ & $463.3 \pm 141.7$ & $1035.5 \pm 334.1^{* * \# \#}$ & $352.2 \pm 69.3$ & $396.1 \pm 207.3^{* * \# \# \Delta \Delta}$ & $228.9 \pm 39.3^{\#}$ \\
\hline $\mathrm{AUC}_{(0-\infty)}$ & $\mathrm{ngh} / \mathrm{mL}$ & $4963.6 \pm 2064.9$ & $529.7 \pm 119.7$ & $1100.4 \pm 393.2^{* * \# \#}$ & $372.4 \pm 62.5$ & $498.7 \pm 254.3^{* * \# \# \Delta}$ & $353.4 \pm 219.5$ \\
\hline $\mathrm{MRT}_{(0-\mathrm{t})}$ & $\mathrm{h}$ & $14.4 \pm 4.4$ & $11.1 \pm 3.4$ & $13.5 \pm 2.6$ & $12.8 \pm 3.3$ & $13.5 \pm 2.0$ & $12.7 \pm 2.2$ \\
\hline
\end{tabular}

${ }^{a}$ Oral administration of the monomer mixture at 470 and $47 \mathrm{mg} / \mathrm{kg}$, and IRC extract at 2000 and $200 \mathrm{mg} / \mathrm{kg}$ were equivalent to that of the oral administration of the PDC monomer at 244 and $24 \mathrm{mg} / \mathrm{kg}$, respectively. ${ }^{*} \mathrm{P}<0.05$ and ${ }^{* *} \mathrm{p}<0.01$ when compared with the level of the corresponding group of conventional rats; ${ }^{\#} p<0.05$ and ${ }^{\# \#} p<0.01$ when compared with the corresponding group that was orally administrated the PDC monomer, and the AUC and $C_{\text {max }}$ values were normalized to the dose when statistics were performed. $\Delta \mathrm{P}<0.05$ and ${ }^{\Delta \Delta} \mathrm{P}<0.01$ when compared with the corresponding group that was orally administrated the monomer mixture 
Moreover, in view that the PDC could be partially converted to RA by the $\beta$-glucosidase of gut microbiota [22], the plasma concentrations of RA in the NPH, NPL, APH, and APL groups were quantified. As shown in $>$ Table $\mathbf{3}$ and Fig. 5, the rate of conversion by gut microbiota seemed relatively slow, which exhibited significantly later mean $\mathrm{T}_{\max }$ values of $6.1 \pm 3.5$ and $8.4 \pm 2.2 \mathrm{~h}$ in the NPH and NPL groups, respectively. The corresponding mean $C_{\max }$ values were $303.1 \pm 111.2$ and $133.5 \pm 33.1 \mathrm{ng} / \mathrm{mL}$, respectively, and the mean $\mathrm{AUC}_{0-\mathrm{t}}$ values were $3716.7 \pm 1113.3$ and $1926.4 \pm 454.9 \mathrm{ng} \mathrm{h} / \mathrm{mL}$, respectively. The $\beta$-glucosidase activity of gut microbiota was markedly reduced after the antibiotic treatment, resulting in the systemic exposure of RA in the APH and APL groups being significantly decreased by more than $58 \%$ compared with the NPH and NPL groups, and the mean $T_{\max }, t_{1 / 2 z}$, and $\mathrm{MRT}_{(0-\mathrm{t})}$ values were all delayed.

However, there was no evidence to rule out the potential effects of these two selected antibiotics on the drug transporters in this study as well as in other reports, but its significant impact on the function of gut microbiota has been proven. Therefore, the potential effects of streptomycin and neomycin on the drug transporters should be illustrated in further study, and a germ-free rat model should be adopted to acquire more accurate results. In summary, this is the first report on the pharmacokinetic comparisons of RA and PDC in conventional and pseudo-germ-free rats after a single oral administration of each monomer, monomer mixture, and IRC extract. These results might provide significant contributions for the clinical use of RA, PDC, and IRC.

\section{Materials and Methods}

\section{Chemicals and reagents}

RA (purity $>99.0 \%$ ) and PDC (purity $>99.0 \%$ ) were isolated in our laboratory from IRC, and their chemical structures ( $\vee$ Fig. 1A) were confirmed with HR-MS and NMR analysis [5,6]. Digoxin (IS, purity $>99.0 \%$ ) was obtained from Weikeqi Biological Technology Co. Ltd. Neomycin sulfate (USP grade) and streptomycin sulfate (USP grade) were purchased from Beijing Biotopped Science and Technology Co., Ltd. p-Nitrophenyl- $\beta$-D-glucopyranoside (purity $>98.0 \%$ ) and $p$-nitrophenol (purity $>98.0 \%$ ) were purchased from Dalian Meilun Biology Technology. Sodium hydroxide ( $\mathrm{NaOH}$, purity $>99.0 \%$ ) was bought from Sigma-Aldrich. MS grade methanol and acetonitrile were acquired from Merck. Ultrapure water used throughout all experiments was purified with a Milli-Q system. The $70 \%$ ethanol extract of IRC was prepared using a previously published method, and the contents of RA $(113.2 \mathrm{mg} / \mathrm{g})$ and PDC $(121.7 \mathrm{mg} / \mathrm{g})$ were determined by a UPLC-MS method [8]. The representative total ion chromatogram of the IRC extract is shown in - Fig. 1D. The RA and PDC monomer mixtures were prepared by mixing $1130 \mathrm{mg}$ RA monomer with $1220 \mathrm{mg}$ PDC monomer.

\section{Apparatus and operation conditions}

The multistage MS experiments were conducted on an AB Sciex Triple-TOF $5600^{+}$mass spectrometer coupled to a Shimadzu LC30 AD chromatography system. Separations were accomplished on a Waters Acquity UPLC BEH $\mathrm{C}_{18}$ column $(100 \times 2.1 \mathrm{~mm}$,
- Table 3 Pharmacokinetic parameters of RA after a single oral administration of the PDC monomer to conventional and pseudogerm-free rats at two dose levels (mean $\pm S D, n=6$ ).

\begin{tabular}{|c|c|c|c|}
\hline \multirow[t]{2}{*}{ Parameters } & \multirow[t]{2}{*}{ Unit } & \multicolumn{2}{|l|}{ PDC monomer } \\
\hline & & 301 mg/kg & $30 \mathrm{mg} / \mathrm{kg}$ \\
\hline \multicolumn{2}{|c|}{ Conventional rats } & NPH group & NPL group \\
\hline$C_{\max }$ & $\mathrm{ng} / \mathrm{mL}$ & $303.1 \pm 111.2$ & $133.5 \pm 33.1$ \\
\hline $\mathrm{T}_{\max }$ & h & $6.1 \pm 3.5$ & $8.4 \pm 2.2$ \\
\hline$t_{1 / 2 z}$ & h & $8.6 \pm 2.5$ & $13.0 \pm 3.7$ \\
\hline$A \cup C_{(0-t)}$ & $\mathrm{ng} \mathrm{h/mL}$ & $3716.7 \pm 1113.3$ & $1926.4 \pm 454.9$ \\
\hline $\mathrm{AUC}_{(0-\infty)}$ & $\mathrm{ng} \mathrm{h/mL}$ & $3828.8 \pm 1063.6$ & $2053.7 \pm 446.8$ \\
\hline $\operatorname{MRT}_{(0-\mathrm{t})}$ & h & $14.5 \pm 2.7$ & $15.2 \pm 1.9$ \\
\hline \multicolumn{2}{|c|}{ Pseudo-germ-free rats } & APH group & APL group \\
\hline$C_{\max }$ & $\mathrm{ng} / \mathrm{mL}$ & $35.2 \pm 9.5^{* *}$ & $30.0 \pm 5.3^{* *}$ \\
\hline $\mathrm{T}_{\max }$ & h & $19.9 \pm 5.8$ & $10.4 \pm 8.4$ \\
\hline $\mathrm{t}_{1 / 2 \mathrm{z}}$ & h & $24.6 \pm 4.2$ & $20.0 \pm 7.8$ \\
\hline$A \cup C_{(0-t)}$ & $\mathrm{ng} \mathrm{h/mL}$ & $793.4 \pm 282.8^{* *}$ & $633.3 \pm 194.0^{* *}$ \\
\hline $\mathrm{AUC}_{(0-\infty)}$ & $\mathrm{ng} \mathrm{h/mL}$ & $1132.2 \pm 296.9^{* *}$ & $855.0 \pm 344.8^{* *}$ \\
\hline $\operatorname{MRT}_{(0-t)}$ & h & $22.7 \pm 5.3$ & $21.5 \pm 1.6$ \\
\hline
\end{tabular}

$1.7 \mu \mathrm{m})$ at $50^{\circ} \mathrm{C}$ with a mobile phase composed of $0.1 \%$ formic acid-acetonitrile ( $\mathrm{v} / \mathrm{v}$, solvent $A)$ and $0.1 \%$ formic acid-water $(\mathrm{v} / \mathrm{v}$, solvent $B$ ). The gradient elution program was as follows: 0 $2.5 \mathrm{~min}, 35-65 \% \mathrm{~A} ; 2.5-3.0 \mathrm{~min}, 65-70 \% \mathrm{~A} ; 3.0-3.5 \mathrm{~min}, 70 \% \mathrm{~A}$; 3.5-4.0 min, 70-100\% A; 4.0-4.5 min, 100-35\% A; 4.5-7.5 min, $35 \% \mathrm{~A}$. The flow rate was $0.4 \mathrm{~mL} / \mathrm{min}$, and the injection volume was $5 \mu \mathrm{L}$. The mass spectrometer was operated in the negative ESI mode. The optimized instrument settings were as follows: ion spray voltage, $-4500 \mathrm{~V}$; source temperature, $550^{\circ} \mathrm{C}$; nebulizer gas pressure and heater gas pressure, 55 psi; curtain gas pressure, 30 psi; declustering potential, $100 \mathrm{eV}$.

\section{Sample preparation}

Preparation of calibration and quality control samples

A mixed stock solution containing $1.90 \mathrm{mg} / \mathrm{mL}$ of $\mathrm{RA}$ and $0.26 \mathrm{mg} / \mathrm{mL}$ of PDC was prepared in methanol. Then a series of working standard solutions were prepared by serially diluting the mixed stock solution with methanol. The calibration standard samples were freshly prepared by spiking the relevant working standard solutions with blank rat plasma to obtain final concentrations of $2400,1200,600,150,75,37.5,18.75,9.38,4.69$, and $2.88 \mathrm{ng} / \mathrm{mL}$ for RA, and 800, 400, 200, 100, 50, 25, 12.5, 6.25, 3.13 , and $1.52 \mathrm{ng} / \mathrm{mL}$ for PDC. QC samples were at 2400, 150, and $4.69 \mathrm{ng} / \mathrm{mL}$ for RA, and 800,50 , and $3.13 \mathrm{ng} / \mathrm{mL}$ for PDC. The IS working solution (1000 ng/mL) was prepared in methanol.

\section{Preparation of plasma samples}

For preparing the plasma samples, $100 \mu \mathrm{L}$ of thawed plasma samples were vortex-mixed with $10 \mu \mathrm{L}$ of IS working solution and $400 \mu \mathrm{L}$ of methanol for $3 \mathrm{~min}$, and then centrifuged at $10008 \times \mathrm{g}$ for $15 \mathrm{~min}$. The supernatant was transferred into another Eppen- 

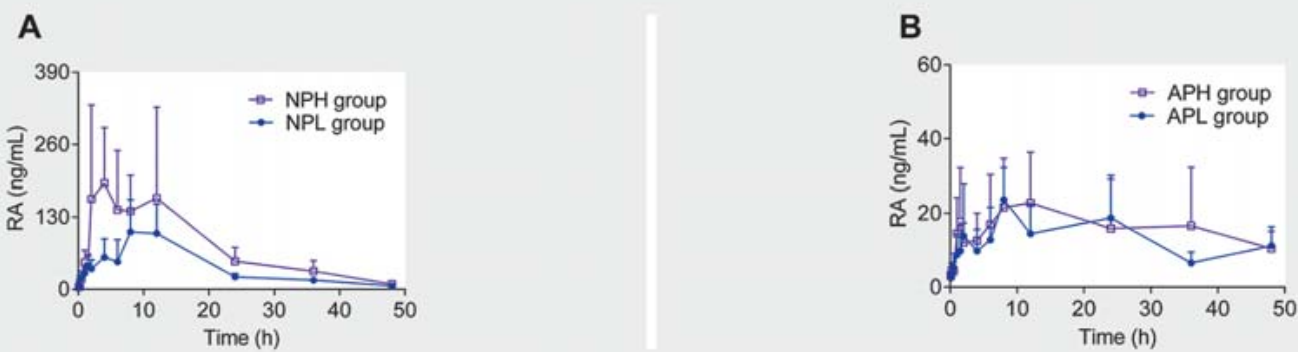

- Fig. 5 Mean plasma concentration-time curves of RA in conventional (A) and pseudo-germ free (B) rat plasma after a single oral administration of the PDC monomer at two dose levels. PDC, pedunculoside; RA, rotundic acid.

dorf tube and evaporated to dryness under vacuum at $30^{\circ} \mathrm{C}$. Each dried residue sample was reconstituted in $100 \mu \mathrm{L}$ of methanol (containing $0.1 \%$ formic acid), followed by centrifugation at $10008 \times g$ for $15 \mathrm{~min}$. Finally, $5 \mu \mathrm{L}$ of the supernatant was used for analysis.

\section{Qualitative method validation}

Selectivity was ascertained by comparing the chromatograms of six blank rat plasma samples, blank plasma spiked with the analytes and IS, and plasma samples from rats after oral administration of the IRC extract. The calibration curves were determined by plotting the peak area ratio $(y)$ of the analytes to the IS versus the nominal concentration $(x)$ of analytes with weighted $\left(1 / x^{2}\right)$ least square linear regression. The LLOQ was determined as the concentrations with a signal-to-noise ratio of 10 . For precision and accuracy studies, QC samples were prepared in six replicates and tested on the same day and three consecutive days, respectively. The extraction recovery was calculated by comparing the peak area ratios of the analytes in regularly pretreated QC samples with those in post-extracted plasma samples. The matrix effect was assessed via comparison of the peak area ratios in the post-extracted samples to those in neat solution at the same concentration. The stability of the analytes at long-term storage (30 days at $-80^{\circ} \mathrm{C}$ ), short-term storage (at room temperature for $24 \mathrm{~h}$ ), and three freeze-thaw cycles $\left(-20^{\circ} \mathrm{C}\right.$ to room temperature as a cycle) was investigated by analyzing six replicates of the QC samples.

\section{Animal model}

A total of 96 specific pathogen-free Sprague-Dawley rats, male, and weighing 220-240 g were purchased from the Animal Laboratory Center, Guangzhou University of Chinese Medicine. All rats were housed under standard conditions of temperature, humidity, and light, and were provided with a standard diet and water. The experiments were approved by the Animal Ethics Committee of Guangzhou University of Chinese Medicine (May 16th, 2017, No. S20170516002), and were conducted in compliance with the Guidelines for Animal Experimentation of the university. All rats were acclimatized for 1 week before the experiment and then randomly divided into two groups (48 rats per group): ATM-treated and conventional groups. The ATM-treated group rats were orally administered with a nonabsorbable antibacterial mixture consisting of streptomycin $(100 \mathrm{mg} / \mathrm{kg} /$ day $)$ and neomycin $(100 \mathrm{mg} / \mathrm{kg} /$ day) for 7 consecutive days, while the conventional group rats received the same volume of $0.9 \%$ normal saline $[23,24]$. The feces samples were collected separately on the 7 th day and stored at $-80^{\circ} \mathrm{C}$.

\section{Assay of $\beta$-glucosidase activity}

The assay was performed according to a previously reported method [25]. Briefly, approximately $0.2 \mathrm{~g}$ of feces were suspended in $3.8 \mathrm{~mL}$ of precooled sterile phosphate-buffered saline $\left(4^{\circ} \mathrm{C}\right.$ ). After centrifugation at $2 \times \mathrm{g}$ for $5 \mathrm{~min}$ (at $4^{\circ} \mathrm{C}$ ), $0.2 \mathrm{~mL}$ of the supernatant was transferred to another Eppendorf tube, and then $0.4 \mathrm{~mL}$ of $2 \mathrm{mM}$ p-nitrophenyl- $\beta$-D-glucopyranoside and $0.4 \mathrm{~mL}$ of $0.1 \mathrm{M}$ phosphate-butter were added. The reaction mixture was incubated for $20 \mathrm{~min}$ at $37^{\circ} \mathrm{C}$, followed by the addition of $200 \mu \mathrm{L}$ of $0.5 \mathrm{~N} \mathrm{NaOH}$ to stop the reaction. Subsequently, the mixture was centrifuged at $6950 \times g$ for $5 \mathrm{~min}$, and the supernatant was applied to measure the enzyme activity using an enzyme immunoassay analyzer at $405 \mathrm{~nm}$.

\section{Pharmacokinetic studies}

Once the pseudo-germ-free rat model was successfully established, the ATM-treated rats were randomly assigned into eight subgroups (6 rats per group): ARH, ARL, APH, APL, AMH, AML, $A E H$, and AEL groups. The conventional rats were randomly divided into eight subgroups as well (6 rats for per group): NRH, NRL, $\mathrm{NPH}, \mathrm{NPL}, \mathrm{NMH}, \mathrm{NML}, \mathrm{NEH}$, and NEL groups. The daily adult dose of IRC is $9.0-30.0 \mathrm{~g}$ in the Chinese pharmacopoeia, which means the daily intake of IRC extract for a rat is $0.3-1.0 \mathrm{~g}$ accordingly. Therefore, the two dosage levels of IRC extract in this study were determined as 2000 and $200 \mathrm{mg} / \mathrm{kg}$, which were equivalent to 226 and $23 \mathrm{mg} / \mathrm{kg}$ of RA, and 244 and $24 \mathrm{mg} / \mathrm{kg}$ of PDC, respectively. Moreover, to compare the pharmacokinetics of RA and PDC, the dosages of PDC monomer were adjusted to 301 and $30 \mathrm{mg} / \mathrm{kg}$, with an equivalent molar concentration to RA. The dosages of the different groups were as follows: AEH and NEH groups: administered IRC extract at $2000 \mathrm{mg} / \mathrm{kg}$; AEL and NEL groups: administered IRC extract at $200 \mathrm{mg} / \mathrm{kg}$; ARH and NRH groups: administered the RA monomer at $226 \mathrm{mg} / \mathrm{kg}(462 \mu \mathrm{mol} / \mathrm{kg})$; ARL and NRL groups: administered the RA monomer at $23 \mathrm{mg} / \mathrm{kg}$ $(46 \mu \mathrm{mol} / \mathrm{kg})$; APH and NPH groups: administered the PDC monomer at $301 \mathrm{mg} / \mathrm{kg}(462 \mu \mathrm{mol} / \mathrm{kg}) ;$ APL and NPL groups: administered the PDC monomer at $30 \mathrm{mg} / \mathrm{kg}(46 \mu \mathrm{mol} / \mathrm{kg}) ; \mathrm{AMH}$ and 
NMH groups: administered the monomer mixture at $470 \mathrm{mg} / \mathrm{kg}$; AML and NML groups: administered the monomer mixture at $47 \mathrm{mg} / \mathrm{kg}$.

The pharmacokinetic studies were conducted on the 8th day, and food was prohibited for $12 \mathrm{~h}$ before the experiment, but water was freely available. Heparinized blood samples $(0.5 \mathrm{~mL})$ were obtained from the suborbital venous plexus at $0,0.083$, $0.25,0.5,0.75,1,1.5,2,3,4,6,8,12,24,36$, and $48 \mathrm{~h}$, and immediately centrifuged at $1114 \times g$ for 10 min to obtain the plasma. The supernatants were collected and frozen at $-80^{\circ} \mathrm{C}$ until analysis. The major pharmacokinetic parameters were calculated using non-compartmental analysis with DAS 2.0 software and are presented as means \pm standard deviation. Statistical comparisons for the pharmacokinetic parameters were determined by unpaired two-tailed Student's t-test using GraphPad Prism 5 software, with $\mathrm{p}<0.05$ considered significant.

\section{Supporting information}

Intraday and inter-day precisions, accuracy, extraction recovery, matrix effect, and stability of PDC and RA in rat plasma are available as Supporting Information.

\section{Acknowledgements}

This work was jointly supported by the National Natural Science Foundation of China (grant numbers 81673565 and 81270054 ) and the Science and Technology Planning Project of Guangdong province (grant number 2017A020213022).

\section{Conflict of Interest}

The authors have declared no conflict of interest.

\section{References}

[1] Liu WJ, Peng YY, Chen H, Liu XF, Liang JY, Sun JB. Triterpenoid saponins with potential cytotoxic activities from the root bark of Ilex rotunda Thunb. Chem Biodivers 2017; 14: e1600209

[2] Amimoto K, Yoshikawa K, Arihara S. Triterpenes and triterpene glycosides from the leaves of Ilex rotunda. Phytochemistry 1993; 33: 14751480

[3] Chinese Pharmacopoeia Commission. The pharmacopoeia of the People's Republic of China, 2015 edition. Beiing: Chemical Industry Press; 2015: 312-313

[4] Fan Z, Zhou L, Xiong T, Zhou J, Li Q, Tan Q, Zhao Z, Jin J. Antiplatelet aggregation triterpene saponins from the barks of Ilex rotunda. Fitoterapia 2015; 101: 19-26

[5] Yang B, Zhu J, Rong L, Jin J, Cao D, Li H, Zhou X, Zhao Z. Triterpenoids with antiplatelet aggregation activity from Ilex rotunda. Phytochemistry 2018; 145: 179-186

[6] Luo HF, Lin CZ, Zhao ZX, Xiong TQ, Zhu CC. Triterpenoids from barks of Ilex rotunda (I). Chin Tradit Herbal Drugs 2011; 42: 1945-1947

[7] Liu C, Shen Y], Tu QB, Zhao YR, Guo H, Wang J, Zhang L, Shi HW, Sun Y. Pedunculoside, a novel triterpene saponin extracted from Ilex rotunda, ameliorates high-fat diet induced hyperlipidemia in rats. Biomed Pharmacother 2018; 101: 608-616

[8] Yang B, Li H, Ruan QF, Xue YY, Cao D, Zhou XH, Jiang SQ, Yi T, Jin J, Zhao ZX. A facile and selective approach to the qualitative and quantitative analysis of triterpenoids and phenylpropanoids by UPLC/Q-TOF-MS/MS for the quality control of Ilex rotunda. J Pharmaceut Biomed 2018; 157: $44-58$

[9] Zhu J, Yang B, Yang T, Tan Q, Tong J, Tong P, Rong L, Zhao Z. Simultaneous determination of four constituents in Cortex Ilicis Rotundae with HPLC. Tradit Chin Drug Res Clin Pharmacol 2015; 26: 558-560

[10] Hsu YM, Hung YC, Hu L, Lee Y], Yin MC. Anti-diabetic effects of madecassic acid and rotundic acid. Nutrients 2015; 7: 10065-10075

[11] Zhang D, Lei T, Lv C, Zhao H, Xu H, Lu J. Pharmacokinetic studies of active triterpenoid saponins and the total secondary saponin from Anemone raddeana Regel. J Chromatogr B 2017; 1044-1045: 54-62

[12] Lin A, Su X, She D, Qiu K, He Q, Liu Y. LC-MS/MS determination and comparative pharmacokinetics of strychnine, brucine and their metabolites in rat plasma after intragastric administration of each monomer and the total alkaloids from Semen Strychni. J Chromatogr B 2016; 1008: $65-73$

[13] Xu M, Wang G, Xie H, Huang Q, Wang W, Jia Y. Pharmacokinetic comparisons of schizandrin after oral administration of schizandrin monomer, Fructus Schisandrae aqueous extract and Sheng-Mai-San to rats. J Ethnopharmacol 2008; 115: 483-488

[14] Chen F, Wen Q, Jiang J, Li HL, Tan YF, Li YH, Zeng NK. Could the gut microbiota reconcile the oral bioavailability conundrum of traditional herbs? J Ethnopharmacol 2016; 179: 253-264

[15] Guo P, Wu C. Gut microbiota brings a novel way to illuminate mechanisms of natural products in vivo. Chin Herb Med 2017; 9: 301-306

[16] Wang Y, Shou J, Jiang J. Metabolism of Chinese materia medica in gut microbiota and its biological effects. Chin Herb Med 2015; 7: 109-115

[17] Swanson HI. Drug metabolism by the host and gut microbiota: a partnership or rivalry? Drug Metab Dispos 2015; 43: 1499-1504

[18] Yang B, Li H, Ruan Q, Tong Y, Liu Z, Xuan S, Jin J, Zhao Z. Rapid profiling and pharmacokinetic studies of multiple potential bioactive triterpenoids in rat plasma using UPLC/Q-TOF-MS/MS after oral administration of llicis Rotundae Cortex extract. Fitoterapia 2018; 129: 210-219

[19] Ji B, Zhuo L, Yang B, Wang Y, Li L, Yu M, Zhao Y, Yu Z. Development and validation of a sensitive and fast UPLC-MS/MS method for simultaneous determination of seven bioactive compounds in rat plasma after oral administration of Guizhi-gancao decoction. J Pharmaceut Biomed 2017; 137: 23-32

[20] Zhou W, Tam KY, Meng M, Shan J, Wang S, Ju W, Cai B, Di L. Pharmacokinetics screening for multi-components absorbed in the rat plasma after oral administration of traditional Chinese medicine Flos Lonicerae Japonicae-Fructus Forsythiae herb couple by sequential negative and positive ionization ultra-high-performance liquid chromatography/tandem triple quadrupole mass spectrometric detection. J Chromatogr A 2015; 1376: 84-97

[21] Sun Y, Xue J, Li B, Lin X, Wang Z, Jiang H, Zhang H, Wang Q, Kuang H. Simultaneous quantification of triterpenoid saponins in rat plasma by UHPLC-MS/MS and its application to a pharmacokinetic study after oral total saponin of Aralia elata leaves. J Sep Sci 2016; 39: 4360-4368

[22] Cao D, Fan Z, Jinping Z, Yang B, Zhou L, jing J, Zhongxiang Z. Effect of rat intestinal bacteria on metabolism of pedunculoside in vitro. China Pharmacist 2016; 19: 621-624

[23] Kang A, Zhang S, Zhu D, Dong Y, Shan J, Xie T, Wen H, Di L. Gut microbiota in the pharmacokinetics and colonic deglycosylation metabolism of ginsenoside $\mathrm{Rb}_{1}$ in rats: Contrary effects of antimicrobials treatment and restraint stress. Chem Biol Interact 2016; 258: 187-196

[24] Jin M], Kim U, Kim IS, Kim Y, Kim DH, Han SB, Kim DH, Kwon OS, Yoo HH. Effects of gut microflora on pharmacokinetics of hesperidin: a study on non-antibiotic and pseudo-germ-free rats. J Toxicol Environ Health A 2010; 73: 1441-1450

[25] Guo Y, Qian J, Di L, Kang A. Pharmacokinetic study on ginsenoside $\mathrm{Rg}_{3}$ and ginsenoside $\mathrm{Rh}_{2}$ in gut microbiotadysbiosis rats. Chin Tradit Herbal Drugs 2016; 47: 4198-4203 